\title{
A Survey of Aflatoxin Contamination of Coconut Products in Sri Lanka; Incidence, Origins and Recommendations
}

U. SAMARAJEEWA

Department of Agricultural Chemistry, Faculty of Agriculture, University of Peradeniya, Peradeniya, Sri Lanka

AND

S. N. ARSECULERATNE

Department of Microbiology, Faculty of Medicine, University of Peradeniya, Peradeniya, Sri Lanka.

(Date of receipt : 10 June 1983)

(Date of acceptance : 23 December 1983)

\begin{abstract}
Forty five large scale mills in the 'Coconut Triangle' of Sri Lanka were studied over a one year period, for aflatoxin contamination of their products - mainly copra, oil and press cake - to determine the incidence and levels of aflatoxin contamination, and the origin of such contamination.
\end{abstract}

Of 344 samples, approximately $50 \%$ contained medium-high levels $(0.05$ to $1 \mu \mathrm{g} / \mathrm{g} . \mathrm{ppm})$ of aflatoxin B1. None of the samples had levels over $1 \mathrm{ppm}$. In 99 selected copra kernels with heavy fungal colonisation, the levels ranged from 0.05 to $4 \mathrm{ppm}$ in $50 \%$ of the kernels. Only 2 kernels had higher levels with 10 and 20 ppm: $29 \%$ of kernels had levels between a trace and $0.05 \mathrm{ppm}$ while no aflatoxin was detected in $18 \%$. The levels detected in cured copra products were lower than those reported in other oilseeds; reasons are discussed.

The aflatoxin levels in the products from 25 mills which were in continuous production during the survey period, were classifiable as 'regularly high', 'occasionally high', 'regularly medium-low' and 'low or nil'. These patterns were correlated with rainfall techniques for curing of copra, conditions of storage, prolonged storage of copra, admixture of high quality copra with substandard kernels for oil extraction and the lack of quality control measures.

\section{Introduction}

Oilseeds have been shown to be good substrates for the growth of aspergilli and aflatoxin production. The major oilseed in Sri Lanka is cocdnut; its products are important food items for both humans and animals in this and several other tropical countries, apart from being items in their export economy.

The economic losses incurred in copra manufacture in Sri Lanka due to fungal spoilage, have been estimated to be approximately $25 \%$ of the total production.? Extensive data on the biological effects of the aflatoxins, with reports of acute intoxication in both humans and farm animals, with indirect evidence for a possible aetiological relationship between the aflatoxin loads in foods and the incidence of cancer of the human liver, necessitated a detailed study of the aflatoxin problem in 
relation to coconut products. This need was accentuated by the demonstration ${ }^{2}$ that fresh coconut was an excellent medium for the accumulation of large amounts of aflatoxin. The economic implications of fungal spoilage in terms of the losses of substrate and lowering of export quality were further reasons for an in-depth study.

A preliminary survey of retail samples of coconut products in the Kandy District ${ }^{1}$ did show economically significant levels of contamination. The present survey was undertaken to provide more detailed data on the incidence and origins of aflatoxin contamination in cc conut products in the major coconut producing area in Sri Lanka, with special reference to the formulation of remedial measures for the prevention and control of contamination.

Coconut based animal feedstuffs were also included in this study on account of the adverse effects of aflatoxin ingestion by farm animals such as on meat production and egg output. as well as on the possibility of ingestion by humans of milk containing the toxic metabolite aflatoxin Ml derived from aflatoxin Bl after ingestion by lactating animals.

\section{Experimental}

2.1 Samples - Samples were collected from 45 out of 58 registered coconut oil mills in the area within the 'coconut triangle' bounded by Chilaw, Kurunegala and Colombo, and along the coastal belt from Puttalam to Beliatta. The few mills in the Jaffna peninsula were not surveyed as this was not a major coconut industrial area. Thirteen registered mills in the 'coconut triangle' which were not functioning during the survey period were excluded from this study.

Samples of the major coconut products-copra, copra press cake (copra meal, poonac) and coconut oil were collected during the three seasons January to April, May to August and September to December in 1973, to investigate the effect of rainfall as reflected in the wet and dry periods of these seasons. In addition, samples of parings, parings oil, parings press cake, coconut refuse ('Polkudu'), refuse oil, refuse press cake, animal feed containing coconut, and desiccated coconut (both export quality and rejected) were also collected for assay from these mills whenever they were available.

Single copra kernels which showed heavy fungal colonisation with aspergilli and penicillia were selected from copra stores for separate analysis.

2.2 Sampling Coconut Oil - Samples were withdrawn from bulk storage tanks by lowering a bottle into the oil. The oil in the tanks was assumed to be homogeneous as regular addition and removal of oil was expected to result in some degree of mixing of the contents of the tank; no other means of homogenising the contents of the tank, was available.

2.3 Copra powder and press cake - Samples (10 g) were withdrawn from adjacent layers, $30 \mathrm{~cm}$ in height in the case of conical heaps. The number of samples 
withdrawn from each of such layers starting from the top of the heap, were in the ratio of volumes $1: 7: 19: 37: 61: 91 \ldots \ldots$, these being the ratios of volumes in a cone when horizontal layers of equal thickness were considered. When long beds of material were sampled, they were assumed to be a series of cones and the samples were withdrawn accordingly. analysis.

The withdrawn samples were then mixed and subsamples were used for

2.4 Preparation of samples for assay- The press cake samples were pulverised in a sponge mill No. 3. The resulting product had the following sieve (BS) analysis:

$\begin{array}{ll}10 \text { mesh retained approximately } & 10 \% \\ 10-20 \text { mesh retained approximately } & 50 \% \\ 20 \text { mesh through approximately } & 40 \%\end{array}$

The copra samples were minced to a particle size of $2 \mathrm{~mm}$ or less.

2.5 Aflatoxin assay - The samples were extracted by a modified $70 \%$ aqueous acetone procedure with 3 successive homogenisations instead of shaking as in the original procedure: ${ }^{8}$ Titration of the extracts in chloroform was done on $250 \mathrm{~nm}$ silica gel $G$ (Merck) thin layer plates, by visual comparison with inocula of pure aflatoxin $\mathrm{B} 1$ and $\overline{\mathrm{G}} \mathrm{l}$ in chloroform, under UV light at $365 \mathrm{~nm}$. On account of the predominant occurrence of Aflatoxin B1, only the values relating to B1 are shown in the tables and figures.

\section{Results}

\subsection{Aflatoxin levels}

Following the classification of aflatoxin levels in foods suggested by the Tropical Products Institute, London ${ }^{5}$ the samples were assigned to 4 groups as follows:

$\begin{array}{lc}\text { group } & \begin{array}{c}\text { Aflatoxin } B 1 \text { content } \\ \mu \mathbf{g} / \mathrm{g} \text { (part per million) }\end{array} \\ \text { Low or negative } & \text { less than } 0.05 \\ \text { medium } & 0.05 \text { to } 0.25 \\ \text { high } & 0.25 \text { to } 1.0 \\ \text { very high } & \text { more than } 1.0\end{array}$

About $50 \%$ of all the samples tested contained medium or high aflatoxin levels.

The distribution patterns of aflatoxin $\mathrm{B} 1$ in the products are shown in Table 1.

The mean aflatoxin levels detected in copra powder, coconut oil and copra press cake collected from 45 mills are $0.08,0.05$ and $0.09 / \mu \mathrm{g} / \mathrm{g}$ respectively. Among 99 
copra kernels which showed heavy colonization with fungi, only two samples had levels of $10 / \mu \mathrm{g} / \mathrm{g}$ or more, with 10 and $20 / \mu \mathrm{g} / \mathrm{g}$ respectively; both these samples were collected from the same mill but on two different occasions. Aflatoxin B1 levels ranging from 0.05 to $4 \mu \mathrm{g} / \mathrm{g}$ were present in $50 \%$ of the copra kernels. Low levels (below 0.05 $\mu \mathrm{g} / \mathrm{g})$ were detected in $29(29 \%)$ samples. These were only $18(18 \%)$ samples which did not contain detectable aflatoxin.

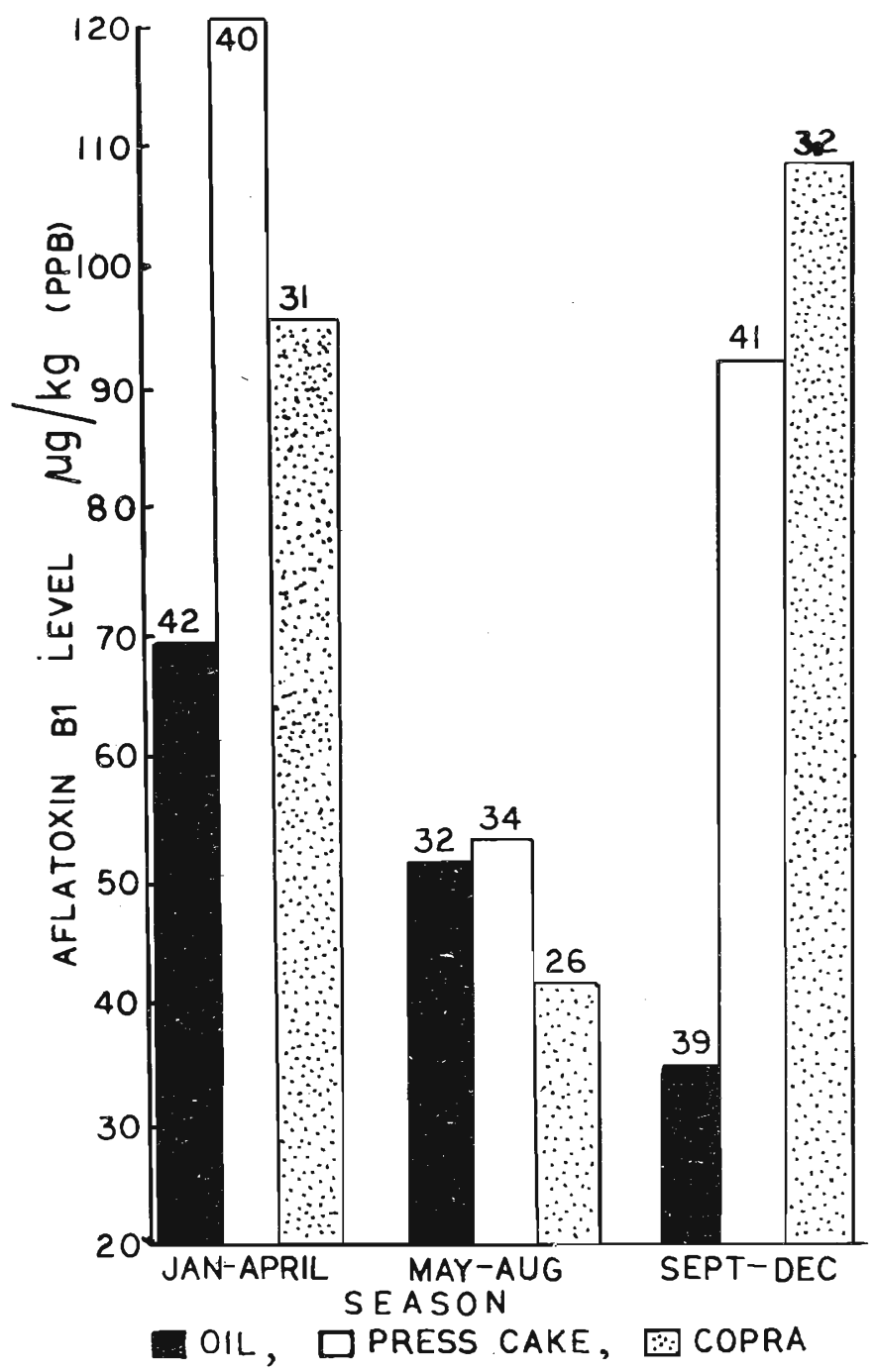

Figure 1. Variation of Aflatoxin Bl contamination patterns in commercial coconut oil, copra press cake and in copra powder with season. Figures on bars refer to the number of samples assayed. Aflatoxin levels represent mean values. 
3.2 Aflatoxin levels in relation to rainfall: The rainfall figures recorded during the survey period showed same pattern of monthly variation in intensity at all the stations along the coast from Puttalam to Beliatta with slightly higher figures in the Kalutara District. The Kurunegala District had low rainfall throughout this period. In all Districts the maximum and minimum rainfall were recorded in the following months:

Month
December (previous year)
January/February
April/May
August/September
October/November

$$
\begin{aligned}
& \text { Pattern } \\
& \text { Maxima } \\
& \text { Minima } \\
& \text { Maxima } \\
& \text { Minima } \\
& \text { Maxima }
\end{aligned}
$$

The mean aflatoxin levels detected in copra powder, coconut oil and copra press cake during the three collections are shown in Figure 1. The aflatoxin levels were high in all the samples of all three products which were collected during January to April period. The levels were lower in samples collected during May-August period. The levels in copra powder and copra pressed cake increased following the high rainfall in August-September while the aflatoxin levels in coconut oil however did not show a corresponding increase during this period. .

\subsection{Aflatoxin B1 levels in samples from individual coconut oil mills}

Data from 20 mills which were not in continuous production during the survey year, was insufficient for a comprehensive analysis and is excluded from this record.

The data presented below is from 25 mills which were sampled continuously throughout the test year; their contamination levels showed a definite pattern and these 25 mills were classified as follows according to the levels of aflatoxin in their samples:

(a) 'Regularly high' Two mills which processed lower grade copra fell into this category. The aflatoxin levels in their products are shown in Figure $2 \mathrm{a}$.

(b) 'Occasionally 'high' High levels of aflatoxin were observed in these 6 mills. These levels were related to high rainfall. Their pattern of contamination is shown in Figure 2b.

(c) 'Regularly medium low' These 4 mills purchased under-smoked or contaminated substandard copra as starting materials, from a few producers. This copra was mixed with good quality copra prior to oil extraction or before deposition for storage. The levels of aflatoxin detected in the samples from these mills are shown in Figure 2c. 


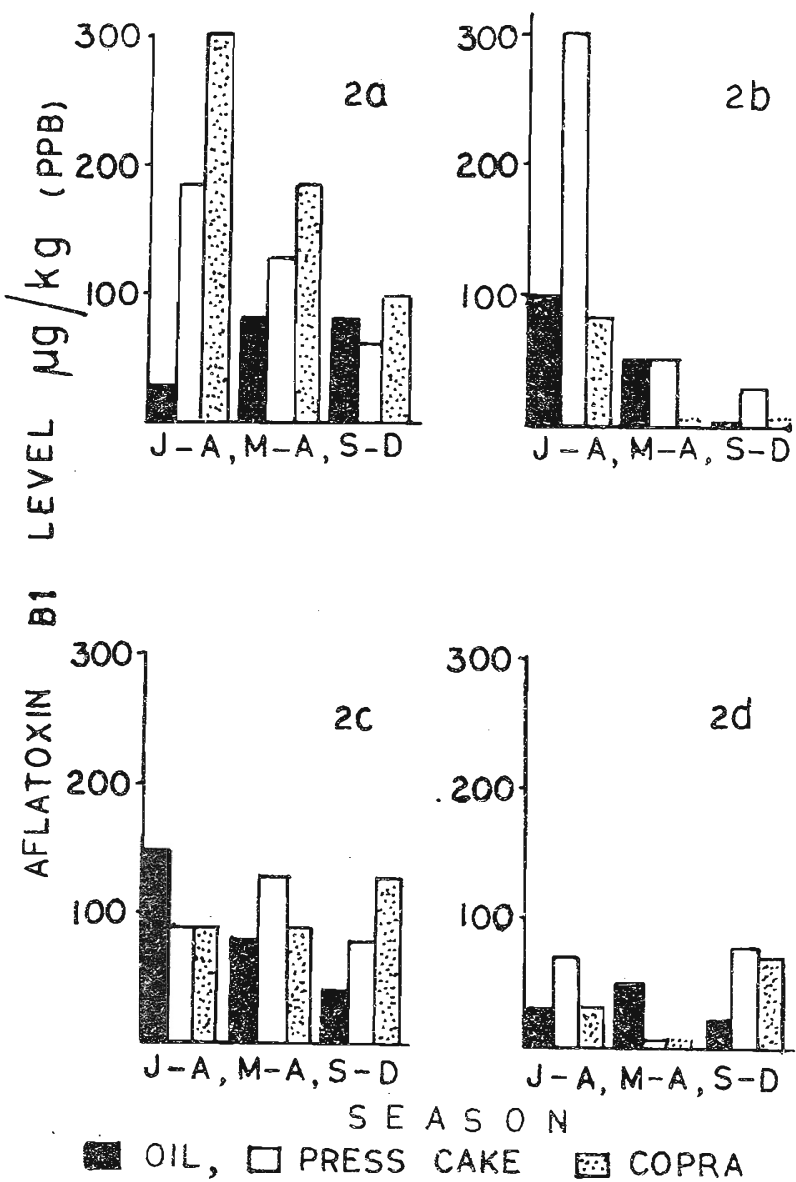

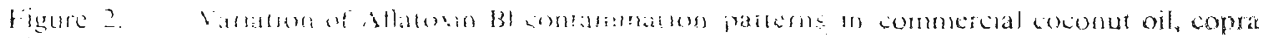
press cake and in copre powder whth season: 2a - mills with regularly high levels:

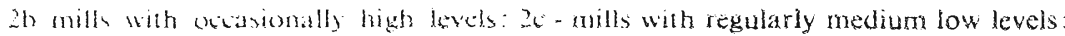

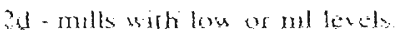

(d) 'Low or high' These 13 copra processing mills were mainly' concerned with expelling oil fromeither coconut parings. which were produced as a by: product of their desiccated coconut industry or had their own smoking kilns which produced high quality copra. Their aflatoxin levels are shown in ligure 2 d. 


\section{Discussion}

4.1 General aspects: The aflatoxin levels detected in copra and its products were appreciably lower in comparison with the levels attained in fresh coconut, experimentally contaminated with Aspergillus parasiticus or Aspergillus flavus ${ }^{2}$. The observation that colonisation of field samples of copra kernels by $A$. flavus-parasiticus was evident in adequately smoked kernels only in and around the areas which were damaged by breakage or rodent attack provided a possible explanation for this paradox, i.e. the mechanical or rodent damage to copra kernels exposed the depths of the kernel which were not exposed to the deposition of the constituents of the smoke. This led to the hypothesis that these smoke constituents were probably inhibitory to fungal colonisation and/or toxin production, a hypothesis which was confirmed experimentally, ${ }^{3}$ For the same reasons the low levels of aflatoxin in smoked copra kernels and the coconut oil contrast with the high levels which are sometimes detected in other oilseeds notably groundnut, which are not smoked but merely dried during their processing.

4.2 The influence of moisture on aflatoxin accumulation in coconut products: Fungal colonisation occurs in copra which contains more than $6 \%$ moisture. The curing of copra reduces the moisture content to $4-6 \%$. However the average moisture content of copra in the field lies between $7-9 \%$ ? During the rainy season, the kernel absorbs moisture from the humid atmosphere resulting in sufficient moisture levels for fungal colonisation. This process is promoted by the practice of some millers who store copra for up to 4 months before expelling oil, as it is claimed by them that, oil is expelled more easily from kernels which have a higher moisture content and which are partially deteriorated.

The higher aflatoxin levels which were detected in the first batch of samples (Figure 1) were probably associated with copra stored through high rainfall which occurred during the last few months (October-December) of the previous year before the collection during January-March. The low rainfall during January-February is reflected in the lower values of aflatoxin in the products which were cured and stored during this period. Storage during this dry period would not have led to rehydration of the processed kernels with consequent aflatoxin formation. The higher levels observed again in samples of the third batch collected during the September-December period are likewise probably correlated with the high levels of humidity consequent on the heavy rains in April-May, during which period these samples were processed and then stored for a few months beyond that period. The coconut production is high during April-May and it is quite probable that large amounts of copra are produced and stored for oil expulsion during lean periods towards the end of the year.

The pattern of contamination of coconut oil however differs from that shown by copra and press cake described above. In the oil, there was a continuous drop of aflatoxin levels with the three samplings during the year. The explanation for the 
decrease of aflatoxin levels in the oil contrasting with a rise in the levels in press cake, is obscure.

4.3 Variation of contamination with mill: Among the four categories of mills, those which belonged to the 'regularly high' category consistently bought low grade copra at cheap rates, to achieve greater profits. The high demand for coconut oil throughout the year and the lack of quality control measures would have also permitted the use of low grade copra for oil extraction and press cake manufacture.

The lack of proper storage facilities and the lack of knowledge on the part of the millers on the origins of fungal colonisation, are apparently serious causes of the high levels of contamination observed in association with rainfall in the 'occasionally high' category of mills.

Although the mills which showed 'regularly medium-low' levels were also compelled to buy substandard copra from outside to keep their mills running throughout the year, their practice of mixing different grades of copra (including high grade copra) as revealed by most of the millers at discussion would have contributed to the overall lower degree of aflatoxin contamination in the samples from these mills. The extent of mixing was found to vary depending on availability of different grades of copra.

The mills of the 'low-nil' category used copra which was cured in their own kilns and did not purchase copra which was cured elsewhere. These two factors would have ensured the use of high quality copra which was reflected in the 'low-negative' values for aflatoxin.

It appears that the problem of fungal contamination is more associated with the lack of the millers' knowledge of the mechanisms of spoilage and its consequences or with financial constraints in setting up their own processing plants, both of which result in the purchase of low quality copra for processing.

\subsection{Millers' practices which encourage fungal spoilage and aflatoxin}

accumulation: During the stage of curing, underdrying of copra is a major problem. Many copra producers admitted that they do not subject copra to more than five rounds of drying. The resulting moisture levels in copra would be above 7 per cent? The main constraint appears to be economic - the reduction of fuel needs and the achieving of higher weights of the copra produced. The millers' belief that mould growth facilitates oil extraction or is an index of optimum drying is a further constraint to the proper curing of copra. Practices such as wiping off, of the fungal growth before mouldy copra is sold - a practice which some producers resort to -does not remove the aflatoxin which is already accumulated in the kernel. At the point of milling, substandard contaminated copra is processed again, for what appears to be economic reasons. Underdried copra is used to provide sufficient stocks of starting 
material to keep the mills running and to ensure a regular stock of oil for sale. In addition this copra is stored for prolonged periods supposedly for easier extraction of oil. Such prolonged storage leads to deterioration of both copra and the extracted oil.

Another practice which results in the overall contamination of bulk oil and press cake is the mixing of substandard,mouldy kernels with high grade kernels, for oil extraction. The disadvantage of this mixing in respect of groundnut was illustrated by Goldblatt" "If just one peanut with a million ppb of aflatoxin is admixed with 10,000 kernels that contain none, the whole lot will assay at the relatively high level of 100 ppb of aflatoxin."

We would therefore recommend that substandard copra be processed separately for oil which could either be refined or diverted to the soap industry while the residual press cake be detoxified prior to use in animal feeds.

The storage conditions in most mills are unsatisfactory. There are often no proper store houses and the copra kernels both adequately dried as well as substandard and mouldy, are left together on the floor of dark, ill-ventilated rooms, exposing them to insect and rodent attack and to humidity. The contaminated mouldy kernels provide the fungal spore inoculum for colonisation of the rest of the heap which occurs with increasing moisture levels with rain, and the exposure of the unsmoked depths of the kernels caused by pest attack. Proper storage to minimize pest damage would be of greater importance with copra kernels than with press cake (poonac) since the occurrence of fungal colonisation and toxin accumulation could result from absorption of moisture by copra but not in press cake which has been rehydrated. ${ }^{1}$

An integral part of the aflatoxin control program would appear to be the education of the millers and producers on the mechanisms of fungal colonisation and the implications of aflatoxin accumulation and resultant intoxication in both humans and animals.

\subsection{Comparison of coconut products with other oil seeds and their products in respect of aflatoxin contamination.}

Data on the aflatoxin problem in coconut products processed in other tropical countries is scanty; Jones ${ }^{6}$ recorded the following levels from a worldwide information survey of aflatoxin contamination in a variety of substrates:

\begin{tabular}{llcc}
\hline Country & product & $\begin{array}{c}\text { number of } \\
\text { samples }\end{array}$ & $\begin{array}{c}\text { aflatoxin content } \\
\text { average level } \\
\text { (ppb) }\end{array}$ \\
\hline Philippines & copra & 171 & 10 \\
Marshall Islands & copra meal & 2 & 6 \\
Caroline Islands & copra & 4 & 30 \\
Western Samoa & copra & 2 & below 5 \\
& & 3 & below 5
\end{tabular}


Table 1. Classification of Coconut products into grades according to Aflatoxin B1 content. Figures refer to number of samples.

Aflatoxin Bl content ( $\mu \mathrm{g} / \mathrm{g}$. parts per million)

\begin{tabular}{lcccc}
\multicolumn{1}{c}{$\begin{array}{c}\text { Product } \\
\text { low or } \\
\text { negative }\end{array}$} & medium & high & $\begin{array}{c}\text { total number } \\
\text { of samples } \\
\text { tested }\end{array}$ \\
\hline Copra powder & 31 & $0.05-0.25$ & $0.25-1$ & 65 \\
Press cake & 34 & 28 & 6 & 92 \\
Coconut oil & 52 & 49 & 9 & 95 \\
Pairings & 10 & 41 & 2 & 13 \\
Pairings press cake & 6 & 3 & 0 & 15 \\
Parings oil & 10 & 7 & 2 & 11 \\
Coconut refuse & & 1 & 0 & 9 \\
'polkudu' & 4 & & & 9 \\
Coconut refuse & 1 & 5 & 0 & 4 \\
press cake & 4 & 8 & 0 & 6 \\
Coconut refuse oil & 6 & 0 & 0 & 5 \\
Industrial coconut oil & 5 & 0 & 0 & 2 \\
Desiccated coconut & 2 & 0 & 0 & 18 \\
Desiccated coconut* & 9 & 0 & 0 & 339 \\
Coconut based animal feeds & 169 & 9 & 19 & \\
Total & & 151 & & 9 \\
\hline
\end{tabular}

* rejected

In general the levels of aflatoxin in coconut products are lower than those which have been reported from technologically underdeveloped countries in other oilseeds and their products. This is in contrast to the excellence of fresh coconut as a substrate for colonisation by Aspergillus flavus-parasiticus and aflatoxin production in comparison, even with groundnut which is reported to be perhaps the most extensively contaminated oilseed. Some of the high levels of aflatoxin which have been reported in groundnuts are as follows (see Jones ${ }^{6}$ ):

\begin{tabular}{lccc}
\hline country & product & $\begin{array}{c}\text { number of } \\
\text { samples }\end{array}$ & $\begin{array}{c}\text { affatoxin content } \\
\text { average level }(\mathrm{ppb})\end{array}$ \\
\hline India & groundnút cake & 2200 & 302.000 \\
& 2340 & 385.000 \\
& 2850 & 996.000 \\
& 580 & 350 \\
& 602 & 290 \\
& 911 & 320 \\
Brazil & 405 & 770 \\
& & 7 & 790 \\
\hline
\end{tabular}


This difference between coconut products and groundnuts is apparently due to the smoking process which the copra kernels are subjected to during their curing, a process which is not applied to other oilseeds including groundnut. The inhibitory effect of smoke on aflatoxin accumulation has been commented on above.

In economic terms however the aflatoxin levels in coconut products are higher than the recommended permissible maximum (WHO/FAO/UNICEF) of $30 \mathrm{ppb}$, in an appreciable proportion of the samples tested. In view of the possible adverse economic consequences of such contamination on the export ind ustry, the attention of the coconut industry is drawn to this problem.

Conversely in biological and toxicological terms, the levels of aflatoxin found in our copra products are perhaps too low to result in acute intoxication of either humans or farm animals. This situation is in contrast to the intoxication of humans and animals, which has been reported to have been due to the consumption of aflatoxin contaminated maize and groundnut respectively. Moreover the inhibitory effect of smoking of aflatoxin accumulation and conversely the excellence of unsmoked coconut as a medium for aflatoxin production was illustrated by the intoxication and deaths of farm goats which had been fed mixtures containing aflatoxin contaminated coconut refuse. ${ }^{9}$

\title{
Acknowledgemants
}

This work was supported by grants from the Coconut Processing Board of the Government of Sri Lanka, and the Natural Reseurces, Energy and Science Authority of Sri Lanka.

\section{References}

\author{
1. Arseculeratne. S. N. \& De Sil.va. L. M. (1971). Cel. J. Med. Sci. $20: 60$. \\ 2. ARSECUleratNe. S. N.. DE SillVA. L. M.. WIJESUNDERA. S. \& BANDUNATHA. C. H. S. R. (1969) \\ Appl. Microbiol., $18: 88$ \\ 3ONES, B. D. (1976). Aflatoxin in. Feedstuffs - its incidence, significance and control. Tropical Products \\ Institute, London \\ 7. NATHANAEl.. W. R. N. (1960). Cey: Coc. Quart., 11:5 \\ 8. PONS, W. A. Jr. CUCULLU. A. F.. LEE. L. S., ROBERTSON. J. A., FRANZ, A. O., \& GOLDBLATT, I.. A \\ (1966). J. Assoc, off. Anal. Chem, 49:554

